\title{
CORRIGENDUM
}

Genes \& Development 31: 1162-1176 (2017)

\section{Corrigendum: SPATA2 regulates the activation of RIPK1 by modulating linear ubiquitination}

Ran Wei, Lily Wen Xu, Jianping Liu, Yanxia Li, Pei Zhang, Bing Shan, Xiaojuan Lu, Lihui Qian, Zheming Wu, Kangyun Dong, Hong Zhu, Lifeng Pan, Junying Yuan, and Heling Pan

It has come to the authors' attention that the blots labeled JNK, p-ERK, p38, SPATA2, and Tubulin in the original Figure $6 \mathrm{~A}$ and $\mathrm{p}$-JNK in the original Figure $7 \mathrm{~F}$ of this article were introduced by error during the figure preparation. The errors occurred because duplicated exposures of some blots were not appropriately labeled immediately and were later mistaken for another experiment at the time of figure preparation. The incorrect blots labeled JNK, p-ERK, p38, SPATA2, and Tubulin in Figure 6A and p-JNK in Figure 7F have been replaced in the article online with the correct blots that were performed at the time that the experiments were originally performed. The conclusions drawn from these blots are unchanged.

In addition, the labels of p-p38 and p38 blots in Supplemental Figure S9A were switched. This has been corrected in the Revised Supplemental Material online.

The conclusion of this article is not affected.

The authors apologize for these errors.

$10.1101 / \operatorname{gad} .321075 .118$ 


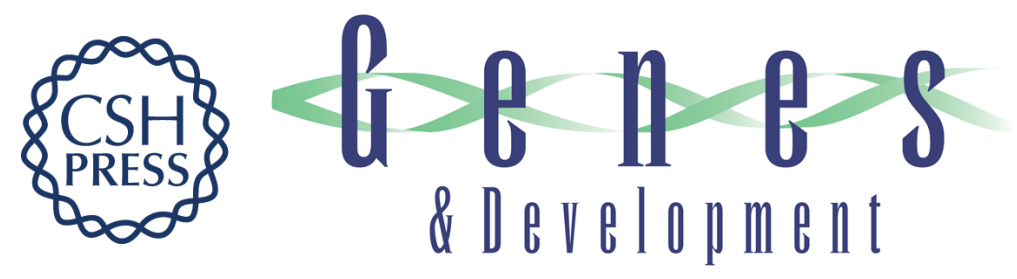

\section{Corrigendum: SPATA2 regulates the activation of RIPK1 by modulating linear ubiquitination}

Ran Wei, Lily Wen Xu, Jianping Liu, et al.

Genes Dev. 2018, 32:

Access the most recent version at doi:10.1101/gad.321075.118

\section{Related Content}

SPATA2 regulates the activation of RIPK1 by modulating linear ubiquitination Ran Wei, Lily Wen Xu, Jianping Liu, et al.

Genes Dev. June , 2017 31: 1162-1176

\section{License}

Email Alerting

Receive free email alerts when new articles cite this article - sign up in the box at the top Service right corner of the article or click here.

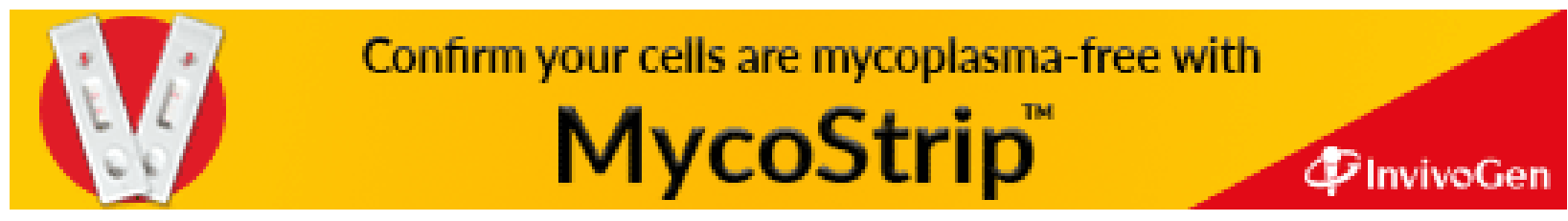

